\title{
EFL teachers' practice of multiple intelligences and the role of their teaching experience
}

Dolati, Zahra

University of Guilan, Iran (dolati.zhr@gmail.com)

Tahriri, Abdorreza $\gtrsim$

University of Guilan, Iran (atahriri@gmail.com)

Danaye Tous, Maryam

University of Guilan, Iran (Maryam.dana@gmail.com)

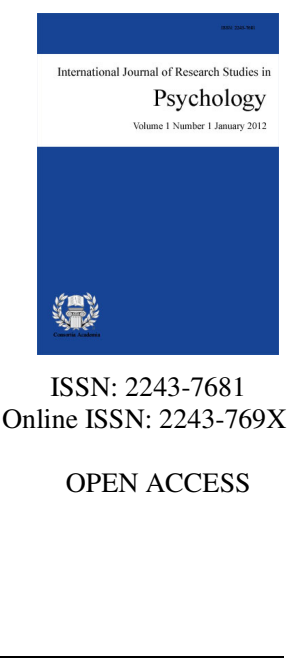

\section{Abstract}

The present study investigated EFL teachers' familiarity with Multiple Intelligences (MI) theory and any possible difference between teachers with different years of teaching experience in terms of the activities implemented in their classes. To this end, 30 male and female EFL teachers took part in the study. The participants' language classes were observed for three successive sessions and their class activities were jotted down through an observation schedule. Semi-structured interviews were also conducted to gather information about the teachers' familiarity with multiple intelligences. Based on the results of Kruskal Wallis test, a significant difference was found simply among teachers with different years of teaching experience in terms of their implementation of logical/mathematical activities ( $p$ $\leq .05)$. No statistically significant difference was found for other types of activities. Furthermore, the majority of the participants of the study (73.3\%) stated that they had no knowledge of the MI theory. In addition, the Chi-square test showed that the instructors were statistically different from each other in terms of their familiarity with Gardner's MI theory. This study can be considered as another step toward understanding what is necessary to put the MI theory into effect.

Keywords: multiple intelligences theory; MI-based teaching; teaching experience, EFL 


\section{EFL teachers' practice of multiple intelligences and the role of their teaching experience}

\section{Introduction}

Generally, one of the factors for a teacher, like many other occupations, to be considered effective is teaching experience. It is believed that experience increases knowledge, skills, productivity, and creativity (Rice, 2010). Numerous studies have been carried out to prove that teaching experience plays a positive role in enhancing teachers' efficacy (Harris \& Sass, 2007; Ladd, 2008; Rice, 2010). Other studies in this area are on finding the relationship between this variable, i.e., teaching experience and some other variables such as students' achievement, the use of different methods of teaching, classroom management approaches, and many others.

One of the cases in researching teaching experience is discovering its relationship with the implementation of various teaching activities. Today, one of the popular teaching methods is the one based on Gardner's MI theory which created a radical departure from the traditional educational system. Gardner (1993) summarizes the educational implications of the MI theory. He believes that an educator should "individualize" and "pluralize". The former term denotes a knowledge of the intelligences profile of each student and an attempt to teach and assess in ways that develop a student's capacities. The latter term means a decision about which topics, concepts, or ideas are of greatest importance and their presentation in a variety of ways. This second step has two important goals. Teaching in multiple ways can guarantee that students with different profiles can benefit from this diversity. Moreover, it helps students to understand the lesson well through multiple modes of delivery. This is what is meant by MI-based teaching.

Numerous studies have so far been allocated to teaching experience and implementation of multiple intelligences in classrooms separately. However, further research was needed to find the relationship between practicing MI teaching and teaching experience like other methods of teaching which are studied in this case. Based on what has been said, the present study investigated EFL teachers' familiarity with the MI theory. It also investigated the differences among teachers with different years of teaching experience in terms of the implementation of MI-based teaching.

\section{Literature Review}

The following two sections will review existing literature in two areas: 1) the research body on teaching experience and its impacts and 2) the theory of multiple intelligences and teachers' awareness of it.

\subsection{Teaching Experience and its Impacts}

As one of the important factors in human resource policies, the years of teaching, i.e., teaching experience influences the effectiveness of teachers during first few years of teaching. After that, its influence will diminish (Rice, 2010; Sass, 2007).

One of the studies in the area of teaching experience was done by Dial in 2008. The researcher examined the relationship between the years of teaching experience and overall achievement of students on communication arts and mathematics. Factorial ANOVA showed that years of experience and the interaction between years of experience and degree level of instructors had a positive effect on students' achievement in both subject areas. As another study of the relationship between teacher experience and student achievement, Zhang (2008) examined students' science achievement with 655 students from sixth to eighth grade and 12 science teachers. Students were tested at the beginning and end of school year by the Discovery Inquiry Test (DIT) in Science. A student demographic information questionnaire and a teacher demographic information questionnaire were also used to gather the data. In this study, it was found that years of teaching experience had no effect on students' science 
achievement. However, the interaction of an advanced degree in science and years of teaching experience was positively associated with students' achievement.

In another study by Ünal and Ünal (2012), the relationship between teaching experience and teachers' classroom management approaches was explored. Two-hundred and sixty-eight primary school teachers took part in this study. The results showed that high-experienced teachers tended to be in control in their classes compared with low-experienced teachers. They also tended to interact with students when making decisions.

In a quite different study, Bayani, Bagheri, and Bayani (2013) examined the relationship between years of teaching experience and burnout. Two-hundred and eighty teachers from secondary schools participated in this study. The data were gathered through a demographic questionnaire and the Persian version of the Maslach Burnout Inventory which measures three components: Emotional exhaustion, depersonalization, and personal accomplishment. Using ANOVA test, the researchers found no significant difference between teachers with various years of teaching experience in terms of their degree of emotional exhaustion, depersonalization, and personal accomplishment.

Soodmand Afshar and Farahani (2015) studied another procedure in relation with teaching experience, i.e., reflective teaching. The 233 participating teachers filled out English Language Teaching Reflection Inventory. Using one-way ANOVA and Tukey post-hoc analysis, the researchers concluded that high-experienced teachers perform better and are more successful regarding the implementation of reflective teaching. While, the research by Jitendra, Harwell, Karl, Dupuis, Simonson, Slater, and Lein (2016) investigated schema-based instruction as implemented by experienced and novice teachers and examined its effect on mathematics outcomes of seventh-grade students, emphasizing problem solving and metacognitive strategy instruction. No statistically significant difference was found between experienced and novice teachers in terms of levels of fidelity to this kind of instruction. And it did not have any effect on students' outcomes.

Kini and Podolsky (2016), in a review paper, assessed 30 studies published within the last 15 years, which examined how teaching experience influences student outcomes. These researchers concluded that teacher effectiveness correlates positively with experience, that is, students taught by more experienced teachers achieve better outcomes. Experience is highly effective in teachers' beginning years, that is, as teachers gain experience in their first years, they change to a more effective teacher very fast. Teacher experience not only affects students' outcomes positively, but also it influences other measures of success like school attendance. When teachers gain experience in the same grade level and subject and among a supportive group of colleagues, they improve as a teacher at a greater rate. In the same vein, teachers with more experience help their colleagues and the school as a whole in order that they achieve better outcomes.

As a useful method of teaching, MI-based teaching can also be investigated in relation to teachers' years of teaching which is absent in the literature. Such a study can have a binary advantage. First, it can reveal something new about teaching experience, that is, whether it contributes to the application of MI-based teaching or not. On the other hand, it can lead to new insights about what is necessary to put the MI theory into practice.

\subsection{Multiple Intelligences and Teachers' Awareness of the Theory}

The importance of considering multiple intelligences, i.e., various abilities and preferences of students which help them learn better is confirmed by numerous studies in this area (Hanafin, 2014; Ghamrawi, 2014; Pourmohammadi, 2012; Xie \& Lin, 2009; Yalmanci \& Gozum, 2013). Still, teachers' perceptions and awareness of the MI theory go into two different directions. Some teachers hold a positive view about the theory and consider it as helpful (Hanafin, 2014; Gunst, 2004; Savas, 2012). There have also been some studies in which teachers did not assess the theory as useful and practical (Kumlu \& Yurttas, 2012). This is due to a bunch of reasons including the shortage of time.

As an example, Hanafin (2014) explored the application of the MI theory in classrooms and schools through 
an action research project in which teachers' perceptions about the theory were explored, too. A program was designed for the 30 participating teachers to develop professionally in order to deliver MI-inspired instruction and they were equipped with materials needed. The participating teachers considered the project as a challenge. They needed more planning time, more persistence, more collegiality, and more management support. They concluded that the experiment was a stimulus for fundamental change in their professional thinking and practice. This positive judgment of the project led the teachers to extend the practices and include MI approaches in their instruction.

\subsection{Research Questions and Hypotheses}

In order to address the gap mentioned above, the present study sought to investigate whether or not teaching experience is related to the practice of multiple intelligences in the classroom. It also explored EFL teachers' familiarity with the MI theory. Thus, the following research questions and hypotheses were proposed.

1. Are there any significant differences among teachers with different years of teaching experience regarding the implementation of MI-based teaching?

2. To what extent are EFL instructors aware of the MI theory and are they significantly different from each other in terms of their familiarity with the MI theory?

In line with the research questions, the following null hypotheses were tested:

$>\mathrm{H}_{01}$ : There are no significant differences among teachers with different years of teaching experience regarding the implementation of MI teaching.

$>\mathrm{H}_{02}$ : EFL instructors are not statistically different from each other in terms of their familiarity with the MI theory.

\section{Methodology}

For this study, both observation and surveys were used to obtain the data. Teachers' years of teaching experience and their classroom practice were the major independent variables that were taken into account. Context of the study (English language institute), and coursebook were the control variables.

\subsection{Participants}

Thirty Iranian female and male EFL teachers, teaching English in private language institutes, using the same textbook were selected as the participants of this study based on convenience sampling. The participants consisted of $26(87 \%)$ female and $4(13 \%)$ male EFL teachers. The age range of the most of the teachers was between 25 to 29 years of age with the average of 28.17. The textbook used in the classes observed was American English File which is particularly prepared for adult students. This textbook presents a bigger balance among the types of intelligences (Oliveira, 2009). Based on the textbook and the requirements of the institutes under investigation, the participants used communicative language teaching (CLT) in their classes. The classes, which were observed, consisted of intermediate levels to reduce the potential effects of students' level on the activities that the teachers chose to implement in the classes.

\subsection{Instrumentation}

The data were gathered through two instruments: Structured observation and oral interview.

Structured observation - Non-participant structured observation was used to obtain the required data. The classes were observed for three successive sessions and the activities used in the classroom were noted. An observation scheme was also developed to check EFL teachers' classroom practice. The sampling method for the 
observation was event sampling, so that it could provide a sound description of the total frequency of the observed events.

Oral interview - The teacher participants were interviewed to get information about their awareness of and familiarity with multiple intelligences.

\subsection{Procedure}

In order to gather the data, the teacher participants' classes were observed for three successive sessions. Overall, thirty classes were observed for ninety sessions. The classes were recorded and the activities that were implemented in classes were jotted down based on the observation schedule; each activity could be attributed to one intelligence type. In an event sampling procedure, the number and length of activities were considered as the data for this study. The recordings were later transcribed and both inter-rater and intra-rater reliability were guaranteed. Next, the teachers were interviewed to first get their personal information such as age, gender, years of teaching and second to see how much they are familiar with the MI theory.

\subsection{Data Analysis}

By using the observation schedule based on event sampling, the frequencies of the class activities were determined. Descriptive statistics including mean ranks, percentage, and standard deviation were utilized to describe the data. In order to analyze the data collected from the observation quantitatively, each occurrence of an activity was taken into consideration as a unit. These units were then added up to account for the amount of activities that were attributed to years of teaching. Kruskal Wallis test was run using SPSS (version 23) in order to determine the possible differences among teachers with various years of teaching experience in terms of the activities that were used in the classes. In addition, descriptive statistics were used to check teachers' familiarity with the MI theory. Chi-square test was also run to see how teachers were different in terms of their familiarity with the MI theory.

\section{Results}

\subsection{Differences among EFL Instructors across Teaching Experience with respect to the Types of Activities}

Table 1 presents the mean ranks of the participants with various teaching experience concerning the implementation of activities in EFL classes:

\section{Table 1}

Ranks of the Instructors with Various Teaching Experience with Respect to their Implementation of Activities

\begin{tabular}{lrcc}
\hline & Experience & $\mathrm{n}$ & Mean Rank \\
\hline Frequency of Verbal/Linguistic Activities & lower than 5 years & 21 & 16.88 \\
& 5 to 10 years & 5 & 12.70 \\
& higher than 10 years & 4 & 11.75 \\
Frequency of Visual/Spatial Activities & Total & 30 & \\
\hline Frequency of Logical/Mathematical Activities & lower than 5 years & 21 & 16.26 \\
& 5 to 10 years & 5 & 10.50 \\
& higher than 10 years & 4 & 17.75 \\
Total & 30 & \\
\hline & lower than 5 years & 21 & 16.93 \\
& 5 to 10 years & 5 & 17.60 \\
& higher than 10 years & 4 & 5.38 \\
\hline
\end{tabular}


Dolati, Z., Tahriri, A., \& Danaye Tous, M.

Table 1 ... continued

\begin{tabular}{lrcc}
\hline & Experience & $\mathrm{n}$ & Mean Rank \\
\hline Frequency of Musical/Rhythmic Activities & lower than 5 years & 21 & 15.14 \\
& 5 to 10 years & 5 & 18.80 \\
& higher than 10 years & 4 & 13.25 \\
Frequency of Interpersonal Activities & Total & 30 & \\
\hline Frequency of Naturalist Activities & lower than 5 years & 21 & 15.93 \\
& 5 to 10 years & 5 & 14.80 \\
& higher than 10 years & 4 & 14.13 \\
& Total & 30 & \\
\hline Frequency of Intrapersonal Activities & lower than 5 years & 21 & 15.64 \\
& 5 to 10 years & 5 & 14.50 \\
& higher than 10 years & 4 & 16.00 \\
& Total & 30 & \\
\hline Frequency of Body/ Kinesthetic Activities & lower than 5 years & 21 & 14.62 \\
& 5 to 10 years & 5 & 22.60 \\
& higher than 10 years & 4 & 11.25 \\
& Total & 30 & \\
\hline
\end{tabular}

The rank table is separated into three rows: Instructors with lower than 5 years of experience, instructors with 5 to 10 years of experience, and instructors with higher than 10 years of teaching experience.

For the frequency of Verbal/Linguistic activities, the mean rank of the instructors with lower than five years $(M=16.88)$ was higher than that of the instructors with 5 to 10 years of teaching experience $(M=12.70)$ and higher than instructors with more than 10 years of teaching $(M=11.75)$. Besides, for the frequency of Visual/Spatial activities, the mean rank of the instructors with lower than five years $(M=16.26)$ was higher than that of the instructors with 5 to 10 years of experience $(M=10.50)$ and less than instructors with more than 10 years of teaching $(M=17.75)$. Concerning the frequency of Logical/Mathematical activities, the mean rank of the instructors with lower than five years $(M=16.93)$ was lower than that of the instructors with 5 to 10 years of teaching experience $(M=17.60)$ and higher than instructors with more than 10 years of teaching $(M=5.38)$. With respect to the frequency of Musical/Rhythmic activities, the mean rank of the instructors with lower than five years $(M=15.14)$ was lower than that of the instructors with 5 to 10 years of teaching experience $(M=$ $18.80)$ and higher than instructors with more than 5 years of teaching $(M=13.25)$.

Concerning the frequency of Interpersonal activities, the mean rank of the instructors with lower than five years $(M=15.93)$ was higher than that of the instructors with 5 to 10 years of teaching experience $(M=14.80)$ and higher than instructors with more than 10 years of teaching $(M=14.13)$. For the frequency of Naturalist activities, the mean rank of the instructors with lower than five years $(M=15.64)$ was higher than that of the instructors with 5 to 10 years of teaching experience $(M=14.5)$ and lower than instructors with more than 5 years of teaching $(M=16)$. For the frequency of Intrapersonal activities, the mean rank of the instructors with lower than five years $(M=14.62)$ was lower than that of the instructors with 5 to 10 years of teaching experience $(M=22.60)$ and higher than instructors with more than 10 years of teaching $(M=11.25)$. Finally, for the frequency of Body/Kinesthetic activities, the mean rank of the instructors with lower than five years $(M=16.62)$ was higher than that of the instructors with 5 to 10 years of experience $(M=15.70)$ and higher than instructors with more than 5 years of teaching $(M=9.38)$.

Kruskal Wallis Test was run to see if these differences were statistically significant. The results are given in the following table (Table 2): 
EFL teachers' practice of multiple intelligences and the role of their teaching experience

Table 2

Kruskal Wallis ${ }^{a, b}$ Test (Instructors with various teaching experience with respect to their implementation of activities)

\begin{tabular}{|c|c|c|c|c|c|c|c|c|}
\hline & $\begin{array}{l}\text { Verbal/ } \\
\text { Ling. }\end{array}$ & $\begin{array}{l}\text { Visual/ } \\
\text { Spatial }\end{array}$ & $\begin{array}{l}\text { Logical/ } \\
\text { Math. }\end{array}$ & $\begin{array}{l}\text { Musical/ } \\
\text { Rhythm. }\end{array}$ & Interpersonal & Naturalist & Intrapersonal & $\begin{array}{l}\text { Body/ } \\
\text { Kines. }\end{array}$ \\
\hline Chi-Square & 1.75 & 2.04 & 6.15 & 1.05 & .18 & .15 & 4.60 & 2.40 \\
\hline Df & 2 & 2 & 2 & 2 & 2 & 2 & 2 & 2 \\
\hline Asymp. Sig. & .41 & .35 & .04 & .59 & .91 & .92 & .10 & .30 \\
\hline
\end{tabular}

Note. a. Kruskal Wallis Test, b. Grouping variable: Teaching experience

Based on the results of the test statistics, a significant difference was found simply among instructors with different years of teaching experience in terms of their implementation of Logical/Mathematical activities ( $p$ $\leq .05)$.

Consequently, the first null hypothesis was mainly supported implying that there was no statistically significant difference among EFL instructors across teaching experience with respect to the types of activities they implemented in the EFL classes.

\subsection{Familiarity with the MI Theory}

Table 3 presents the results of the item statistics that dealt with the degree to which EFL instructors are familiar with the Gardner's theory of multiple intelligences.

\section{Table 3}

The Instructors' Familiarity with Gardner's Theory of Multiple Intelligences

\begin{tabular}{rcc}
\hline & Frequency & Percent \\
\hline Not at all & 22 & 73.3 \\
Slightly & 5 & 16.7 \\
Moderately & 3 & 10.0 \\
Total & 30 & 100.0 \\
\hline
\end{tabular}

Concerning the instructors' familiarity with the MI theory, the majority of EFL instructors $(n=22, p=$ $73.3 \%)$ selected not at all. Some of them $(n=5, p=16.7 \%)$ selected slightly, and simply a few $(n=3, p=10 \%)$ reported that they were familiar with it moderately.

The Chi-square test tabulated the instructors' viewpoints into categories and computed the Chi-square statistic. This test compared the observed and expected frequencies in each category to test that all categories contain the same proportion of values.

\section{Table 4}

Chi-Square Test

\begin{tabular}{rc}
\hline \multicolumn{2}{c}{ Test Statistics } \\
\hline Chi-Square & 21.800 \\
Df & 2 \\
Asymp. Sig. & .000 \\
\hline
\end{tabular}

Since the $p$-value is less than the significance level $(\alpha=.05)$, the second null hypothesis can be rejected, $\chi^{2}$ $(2, n=30)=21.80, p<.05$. In other words, the instructors were statistically different from each other in terms of their familiarity with Gardner's theory of multiple intelligences.

\section{Discussion}

The present study sought to investigate EFL teachers' degree of familiarity with the MI theory. It further investigated the differences between teachers with various years of teaching in terms of their use of MI-based teaching. To this end, 30 Iranian female and male EFL teachers took part in oral interviews and their classes were 
observed for three successive sessions in order to find the total frequency of each type of activity related to each intelligence. The findings of the study showed a significant difference among teachers with different years of teaching experience in terms of their implementation of logical/mathematical activities. But no statistically significant difference was found regarding other types of activities. Furthermore, the majority of teachers in this study $(73.3 \%)$ declared that they have no knowledge of the MI theory.

In investigating the relationship between teaching experience and methods of teaching, most often the results are in favor of high-experienced teachers (Soodmand Afshar \& Farahani, 2015; Ünal \& Ünal, 2012). Usually, in these cases, teachers with more teaching years outperform less-experienced teachers. However, in this study, no statistically significant difference was found among teachers with different years of teaching. The difference was only found in terms of the use of logical/mathematical activities. Like the study done by Jitendra et al. (2016) on schema-based instruction, the present study on MI-based teaching proved teaching experience to be ineffective in this method of instruction.

Regarding the participating teachers' familiarity with the MI theory, the findings of Kumlu and Yurttas (2012) are in line with those of the present study. The participants of this research who were science and technology teachers did not have enough information about the MI theory and they did not try to apply it in their classrooms.

\section{Conclusion}

Gardner's theory of multiple intelligences redefined the concept of intelligence and as a result, influenced educational systems in many ways. Using multiple intelligences in teaching can put students with different abilities and strengths into advantage and make them enjoy learning. As Sulaiman, Abdurahman, and Abdurahim (2010) asserted, "Multiple intelligence theory provides a platform and guidance to teachers to use integrated strategies and instructional activities to cater to the different needs of students in terms of intelligence profiles, learning styles and leaning preferences." In addition, "the awareness of the different intelligences and the different teaching strategies can optimize learning motivation and enhance memory in accelerating the learning process" (p. 517).

This study attempted to investigate EFL teachers' familiarity with the MI theory and to find whether there is a difference between teachers with different years of teaching in terms of the implementation of MI-based teaching. In other words, the study investigated whether teachers with different years of teaching experience are inclined to use activities of certain types or not. The findings of the study showed that the majority of the teachers had no knowledge of the MI theory. Furthermore, no statistically significant difference was found among teachers with different years of teaching experience in terms of the implementation of different types of activities except for logical/mathematical activities.

This failure to take proper care over providing MI-based teaching may prohibit learners with different abilities and interests to actualize their potentials. Furthermore, they cannot nurture themselves in different intelligences. The present study also contributed to the body of research on teaching experience and more specifically its relationship with MI-based teaching. Although it can be considered as another step toward understanding what is necessary to put the MI theory into effect, the results should be interpreted carefully because of the limitations of the research including the limited number of the participants.

\subsection{Suggestions for Further Research}

The results of the present study need to be supported by further research on this topic, i.e., the relationship between teachers with different years of teaching experience and the implementation of MI teaching with more participants and across different contexts. Another suggestion for further research can be the comparison of male and female teachers in terms of the implementation of MI-based teaching. 


\section{References}

Bayani, A. A., Bagheri, H., \& Bayani, A. (2013). Influence of gender, age, and years of teaching experience on burnout. Scholars Research Library, 4(4), 239-243.

Dial, J. C. (2008). The effect of teacher experience and teacher degree levels on student achievement in mathematics and communication arts (Unpublished doctoral dissertation). Baker University, Kansas.

Gardner, H. (1993). Multiple Intelligences: The theory in practice. New York: Basic Books.

Ghamrawi, N. (2014). Multiple intelligences and ESL teaching and learning: An investigation in KG II classrooms in one private school in Beirut, Lebanon. Journal of Advanced Academics, 25(1), 25-46. http://dx.doi.org/10.1177/1932202X13513021

Gunst, G. A. (2004). A study of multiple intelligences among teachers in Catholic elementary schools in the Archdiocese of Detroit (Doctoral dissertation). Wayne State University. Retrieved from http://elibrary.wayne.edu/record=3041404

Hanafin, J. (2014). Multiple intelligences theory, action research, and teacher professional development: The Irish MI project. Australian Journal of Teacher Education, 39(4), 126-142. http://dx.doi.org/10.14221/ajte.2014v39n4.8

Harris, D. N., \& Sass, T. R. (2007). Teacher training, teacher quality, and student achievement. CALDER working paper 3. Washington, DC: The Urban Institute.

Jitendra, A. K., Harwell, M. R., Karl, S. R., Dupuis, D. N., Simonson, G. R., Slater, S. C., \& Lein, A. E. (2016). Schema-based instruction: effects of experienced and novice teacher implementers on seventh grade students' proportional problem solving. Learning and Instruction, 44, 53-64. http://dx.doi.org/10.1016/j.learninstruc.2016.03.001

Kini, T., \& Podolsky, A. (2016). Does teaching experience increase teacher effectiveness? A review of the research. Retrieved from https://learningpolicyinstitute.org/our-work/publications-resources/does-teaching-experience-increase-t eacher-effectiveness-review-research

Kumlu, G., \& Yurttas, G. D. (2012). Science and technology teachers' views about considering students' intelligence types in project and performance tasks. Procedia Social and Behavioral Sciences, 47, 1742-1746. http://dx.doi.org/10.1016/j.sbspro.2012.06.893

Ladd, H. F. (2008). Value-added modeling of teacher credentials: Policy implications. Paper presented at the second annual CALDER research conference, "The Ins and Outs of Value-Added Measures in Education: What Research Says", Washington, D.C.

Oliveira, C. L. (2009). Coursebooks and multiple intelligences theory: An analysis (Masteral thesis). The Federal University of Rio Grande do Sul. Retrieved from https://www.lume.ufrgs.br/bitstream/handle/10183/21502/000737485.pdf?sequence=1

Pourmohammadi, M., Zainol Abidin, M. J., \& Yang Ahmad, K. A. (2012). The relationship between students' strengths in multiple intelligences and their achievement in learning English language. Journal of Language Teaching and Research, 3(4), 677-686.

Rice, J. K. (2010). The impact of teacher experience: Examining the evidence and policy implications. CALDER working paper 11. Washington, DC: The Urban Institute.

Sass, T. R. (2007). The determinants of student achievement: Different estimates for different measures. Paper presented at the first annual CALDER research conference, Washington, D.C.

Savas, P. (2012). Pre-service English as a foreign language teachers' perceptions of the relationship between multiple intelligences and foreign language learning. Learning and Individual Differences, 22(6), 850-855. http://dx.doi.org/10.1016/j.lindif.2012.05.003

Soodmand Afshar, H., \& Farahani, M. (2015). Reflective thinking and reflective teaching among Iranian EFL teachers: Do gender and teaching experience make a difference? Procedia Social and Behavioral Sciences, 192, 615-620. http://dx.doi.org/10.1016/j.sbspro.2015.06.107

Sulaiman, T., Abdurahman, A., \& Abdurahim, S. S. (2010). Teaching strategies based on multiple intelligences theory among science and mathematics secondary school teachers. Procedia Social and Behavioral 
Dolati, Z., Tahriri, A., \& Danaye Tous, M.

Sciences, 8, 512-518. http://dx.doi.org/10.1016/j.sbspro.2010.12.070

Ünal, Z., \& Ünal, A. (2012). The impact of years of teaching experience on the classroom management approaches of elementary school teachers. International Journal of Instructions, 5(2), 41-60.

Xie, J., \& Lin, R. (2009). Research on multiple intelligences teaching and assessment. Asian Journal of Management and Humanity Sciences, 4(2-3), 106-124.

Yalmanci, S. G., \& Gozum, A. C. (2013). The effects of multiple intelligence theory based teaching on students' achievement and retention of knowledge (Example of the Enzymes subject). International Journal on New Trends in Education and their Implications, 4(3), 27-36.

Zhang, D. (2008). The effects of teacher education level, teaching experience, and teaching behaviors on student science achievement (Unpublished doctoral dissertation). Utah State University, Logan. 